\title{
Э.А. Бальбуров
}

\section{Спонтанный сюжет}

В сложившейся типологии сюжетов спонтанного сюжета мы не найдем, точно также, как трудно его отыскать в «химически» чистом виде и в самой литератуpe. Спонтанный сюжет - это принцип создания сюжета: подобно природному плоду, вызревающему в материнском лоне, он нарождается в сознании автора, помимо его воли, поэтому слово «сюжетосложение» по отношению к нему надо поменять на слово сюжеторождение. Спонтанный сюжет принципиально нериторичен, не связан с приемами и правилами. Его появление покрыто тайной, как раскрытие цветка или рождение ребенка.

Антиномии рожденного и сделанного пристальное внимание уделила античная философия. Особую актуальность она приобретает в сфере технэ - искусных человеческих умений. Платон выделял среди них такие, которые требовали не одной только рассудительности, но одержимости и вдохновения. Образцом подобных умений Платон, несмотря на его нелюбовь к поэтам, высказанную в «Государстве», счел именно поэзию.

Поэзия дает имя тому роду искусных умений, в которые мастер вкладывал свою душу, как поэт вкладывает ее в свое творчество. Пойесис в платоновском значении этого слова - творение, созидание, делание, постройка, сочинение стихов. Поэзия в собственном смысле была высшей формой пойесис, воплотившей принцип «сделанное как рожденное». Родоначальник античного теоретизма ставил ее выше теории, выше культивируемого риторикой понимания словесной деятельности как технэ. От диалога к диалогу повторяется его мысль о том, что поэзия - сестра прорицательству и священному безумию: «Все хорошие эпические поэты, - утверждал он устами Сократа в диалоге “Ион”, - слагают свои прекрасные поэмы не благодаря технэ, а лишь в состоянии вдохновения и одержимости... Говорят же нам поэты, что они летают, как пчелы, и приносят нам свои песни, собранные у медоносных источников в садах и рощах Муз. И они говорят правду: поэт - существо легкое, крылатое и священное, и он может творить лишь тогда, когда сделается вдохновенным и исступленным и не будет в нем более рассудка; а пока у человека есть этот дар, он не способен творить и пророчествовать» («Ион», 533 d - 534 е; цит. по: [Платон, 1990, с. 376-377]). Та же мысль звучит из уст Сократа и в диалоге «Федр»: «Кто же без неистовства, посланного Музами, подходит к порогу творчества в уверенности, что он благодаря одному лишь технэ станет изрядным поэтом, тот еще далек от совершенства: творения здравомыслящих затмятся творениями неистовых... ибо неистовство, которое у людей от бога, прекраснее рассудительности, свойства человеческого» («Федр», 245 a, 244 d; цит. по: [Платон, 1993, с. С.153-154]). Проблема соотношения творчества и технического умения, искусства и приема не случайно приобретает остроту в переломную для словесной культуры эпоху становления рефлективной традиции - период формирования, формализации и спецификации литературной теории и критики. На дорефлективной стадии словесности эта проблема снималась имплицитным, инкорпорированным характером ее приемов. Так сюжеты мифа и ритуала представляли 
собой естественную сегментацию и схематизацию культовых телесно-речевых действий, которые больше соответствовали не построению, а порождению. Они рождались и возрождались как сама природа, в органическом единстве семантики и синтактики. Однако по мере их экспликации и осознания, мир фактов и вещей постепенно отделялся от мира знаков и суждений. Возникают понятия референции, авторства, модального и временного градиента (действительное и возможное, прошлое и будущее), развивается система логико-грамматических и пропозициональных средств - весь этот арсенал инструментов создания текста и специфицировался в виде поэтики и риторики. Вместе с ним возникает и проблема соотношения творчества и его приемов.

Платон, как уже сказано, занял тут резко антириторическую позицию. Аристотель, напротив, стал основателем и кодификатором системы творческих приемов, поставив, по выражению С.С. Аверинцева, «поэтику под знак риторики». По мнению Аверинцева, дальнейшая судьба литературы оказалась благосклоннее именно к аристотелевской традиции, «соединив более чем на два тысячелетия черту» сознательных литературных исканий «с чертой традиционализма» [Аверинцев, 1981, с. 5]. Это была эпоха становления европейской цивилизации, завершившейся второй культурной революцией человеческой истории - промышленной революцией. Существенным смыслом данной эпохи стала сакрализация человеческого образа и его умений. Авторитет надличной силы уже не был безраздельным господином традиции, весомым становится слово и дело человека, автора-творца произведений науки и искусства, технических орудий и сооружений.

Именно эти причины предопределили, как мне кажется, приоритет аристотелевских, а не платоновских эстетических представлений. Суть первых заключалась в понимании произведения как человеческого создания и изделия, суть вторых - в понимании божественного происхождения произведений искусства, посредством которого боги общаются с людьми. В сфере сюжетики аристотелевская система наиболее последовательно выразилась в нарративном сюжете как специфической художественной форме логического суждения и пропозиции. Он так же предполагал причинно-следственную и хронологическую связь, имел определенные правила построения: «Нужно, чтобы хорошо сложенные сказания не начинались откуда попало и не заканчивались, где попало», они должны быть целыми, а «целое есть то, что имеет начало, середину и конец» («Поэтика», 50 в 32, в 26; цит. по: [Аристотель, 1978, с. 124]). Спонтанный сюжет с точки зрения аристотелевской поэтики - это сказание, сложенное без правил, которое может начинаться и кончаться, где попало.

Но что представлял собой спонтанный сюжет с точки зрения Платона? Это образы и идеи, эйдосы в том виде и порядке, в каком они сообщены Музами сказания, сложенные не человеческой рассудительностью, а божественным откровением, не сочиненные, а рожденные. Они - плоды неистовства и одержимости, которые у людей от бога, а потому плоды эти прекраснее созданий человеческой рассудительности. Примечательно, что слова о божественном смысле рождения в диалоге «Пир» Платон вкладывает не в уста Сократа, чье имя все же срослось с понятиями разума и теории, а прорицательницы Диотимы: «Дело в том, Сократ, говорит она, - что все люди беременны как телесно, так и духовно, и, когда они достигают известного возраста, природа наша требует разрешения от бремени. Разрешиться же она может только в прекрасном, но не в безобразном. Соитие мужчины и женщины есть такое разрешение. И это дело божественное, ибо зачатие и рождение суть проявления бессмертного начала в существе смертном... Те, у кого разрешиться от бремени стремится тело, обращаются больше к женщинам и служат Эроту именно так, надеясь деторождением приобрести бессмертие и счастье и оставить о себе память на вечные времена. Беременные же духовно - ведь есть и такие, - пояснила она, которые беременны духовно, и притом в большей 
даже мере, чем телесно, - беременны тем, что как раз душе и подобает вынашивать... Они гораздо ближе друг другу, чем отец и мать, и дружба между ними прочнее, потому что связывающие их дети прекраснее и бессмертнее. Да и каждый, пожалуй, предпочтет иметь таких детей, а не обычных, если подумает о Гомере, Гесиоде и других прекрасных поэтах, чье потомство достойно зависти, ибо оно приносит им бессмертную славу и сохраняет память о них, потому что и само незабываемо и бессмертно» («Пир», 206 с, 209 a, c, d; цит. по: [Платон, 1993, c. 116]). Сакральность акта рождения Платон противопоставил механистической технологичности ремесла. Им соответствовали два состояния души: когда она следует телу, (слово, означавшее по-древнегречески цель), и когда душа вспоминала свою небесную родину и ее влекло к вещам себе подобным - цельным и божественным. В неоплатонизме это состояние называлось «экстазом», что означает выход из себя, к божественной тайне. Мистика неоплатонизма впоследствии была воспринята российским любомудрием, его особой гносеологией «мистического реализма». Это странное, на первый взгляд, словосочетание обосновывается мистическим опытом, зрением «тела духовного», очами интуиции, способными видеть сверхчувственное как реальную вещь. Когда оно постигается разумом, то перестает быть мистическим и становится идеальным, противостоящим реальному в его исконном значении, производном от латинского res (вещь). Разум определяет сверхчувственное, делает его понятием, выводит на яркий свет языка, секуляризует и уже этим отрицает (всякое определение есть отрицание, говорил Спиноза) его как тайну и существо. Разум и мистика несовместимы: где поселяется логика и рассудительность, уже нет места тайне. Сохранить ее в акте разума невозможно только в акте веры. Именно в нем осуществляется не умственно-идеальная, а реальная связь со сверхчувственным: в языческих культовых действах, оккультных ритуалах, церковных таинствах, наконец, в творческой одержимости поэта, художника.

Проблема спонтанного сюжета, а шире - спонтанной природы творчества как такового - восходит, как видим, к религиозно-философской проблематике богообщения. Окно к Богу, в мир божественной тайны идеалистический рационализм перекрывает «соломой понятий» (выражение Лейбница: «не надо путать солому понятий с зернами вещей»). Произошла подмена живой реальности удобопревратными универсалиями человеческого («слишком человеческого», вспоминая Ницше) разума, и вместо благодатных энергий и божественного света воспринимаются и созерцаются собственные представления, «прелестная», на языке православной аскетики, иллюзия - проекция конечного и несовершенного человеческого ума, фантомов и «миражей его внутренней пустыни» [Аверинцев, 2001, с. 418].

Эти вопросы стали предметом полемического обсуждения в русской религиозно-философской и публицистической мысли в свете любимой и приоритетной для нее темы о России и Европе, о Востоке и Западе. В отличие от Запада, прошедшего длительный процесс секуляризации, формирования светских норм мышления и бытия - гражданского права, государственного устройства, парламентаризма, частной собственности и других священных принципов - «законных наследников религиозно-теократического духа», в России «энергия православной веры направлялась в глубины духовной жизни, не участвуя заметно в формировании гражданской и государственной жизни...Русской душе остались чуждыми мораль и право в светском смысле, как независимые от религии...Если русскому присуща действительная религиозная просветленность, тогда он проявляет признаки удивительного духовного величия и чистоты; или же, если он утерял веру, он становится полнейшим нигилистом» [Франк, 1996, с. 144].

Душа России, говоря словами Платона, не последовала телосу, не была «замазана культурой» (выражение Е. Трубецкого), оставалась внутренне свободной от «окаменелых форм жизни» (П. Чаадаев) - рационалистических схем мышления 
и социального бытия. «Палимпсест заветных преданий», народного сознания - по изящному выражению Вяч. Иванова, - не был «испещрен поздней рукой» цивилизации [Иванов, 1994, с. 27]. Речь не идет о том, что на Западе не было мыслителей, преодолевших рутину стереотипов и канонов, не способных взлететь над всем этим: предписания не для великих. Речь идет об избранном Европой «фаустовском» (опытном) пути и ее позитивистско-рационалистическом складе ума, которому потребовалось, по признанию Канта, пробуждение от догматического сна, коперниканский поворот к бытию и мышлению, вернувшемуся в свою экзистенцию. Но догматический сон - явно не русский сон, а онтологического поворота мы не найдем на столбовой дороге русского философствования, потому что оно было онтологичным исконно.

Россия, ее дух и разум не путали, как говорится, божий дар с яичницей: истину с ее рассудочной тенью, идею - с понятием, живое знание - со схемой, вселенскую цельность организма - с человеческой цельностью механизма. Она не впала в социум, в гипноз практических целей, в жизнь «по понятиям» рассудка, оставаясь верной небу, благодати, божественному наитию. Русский органицизм - это антитеза «фаустовскому пути» Европы, приоритет рожденного над сделанным, Логоса над praxis, энергии свободной над связанной. Примечательным штрихом обозначенной антитетики является различие между русским словом «образование» с его корнем «образ» и английским аналогом данной семы «education» с корневой основой «еducate», первое значение которой - «to lead forth» (вести вперед). В этих различиях ясно просвечивают цельные восточные категории образа, идеографии, парадигмы и западные - линия, синтагма и цель, которая усекала и выпрямляла жизнь в телеологический вектор карьеры, накопительства, прогресса и т.п. Их когнитивными коррелятами были аристотелевские логическая и энтелехиальная схемы (энтелехия, превращающаяся в форму), прямоугольные декартовы координаты, линия нарратива и др.

В свете этих факторов становятся понятными эстетические приоритеты России и Запада. Ориентация русского художественного сознания на христиансконеоплатоническую сакральную концепцию искусства онтологизировала его, искусство в России было больше, чем искусство, поэт - больше, чем поэт. Снятие «заклятия рампы с ее иллюзионизмом» с искусства, переживание его «неземной силы и земного бессилия» (С. Булгаков), неприятие сформировавшегося «в новой западной философии понимания поэзии как чистого вымысла и развлекательности» [Лосев, 1991, с. 214] - лейтмотив русской эстетики. Напротив, длительное доминирование аристотелевской нормативно-риторической системы в западноевропейских эстетических представлениях вело к деонтологизации искусства, к преобладанию знакового начала над символическим. «Что такое поэзия? Вещь ли это настоящая?» - спрашивает героиня одной из шекспировских комедий крестьянка Одрей. Русская литература не задавала себе таких вопросов. «Законы литературной техники на Западе, - писал А. Белый, - перевесили смысл литературных произведений. Стилист победил проповедника. Но победа стиля отдала литератора во власть ремесла» [Белый, 1994, с. 347].

Демонтаж и слом «рефлективно-традиционалистской установки», как показал С. Аверинцев, был в европейской литературе мучительным и длинным, приобрел в ней характер «мятежа против рассудочно-риторической правильности» [Аверинцев, 1981, с. 7]. Прежде всего это коснулось сюжета как смыслообразующего ядра произведений. Одним из первых «мятежников» был Монтень. В своих «Опытах» он декларирует новый для своего времени художественный принцип: «У меня нет другого связующего звена при изложении моих мыслей, кроме случайности... Я излагаю свои мысли по мере того, как они появляются: иногда они теснятся гурьбой, иногда возникают по очереди, одна за другой. Я хочу, чтобы виден был естественный и обычный ход их, во всех зигзагах. Я излагаю их так, как они 
возникли» [Монтень, 1991, с. 19].

Элемент спонтанности усиливается в произведениях сентименталистов и романтиков. В качестве знаковых примеров можно привести романы Стерна и Руссо. Выступая против мертвеющих риторических канонов, Монтень, Стерн, Руссо и другие «мятежники» свою сверхзадачу видели в новом уровне художественной правды, онтологической (в противовес меоническим понятиям рассудка) истине о человеке и прежде всего его внутренней жизни. Спонтанность рождающихся сюжетов и образов была для них равнозначна естественности и достоверности, несочиненности.

В русской литературе слом традиционалистской системы был существенно иным. Ее традиционализм носил не столько рассудочно-риторический, сколько обрядово-этикетный, религиозно-канонический характер: нормы и формулы были даны не теоретической рефлексией художественной практики, а самой жизнью. Писатель заимствует их из ее разных областей: «из церковных представлений, из представлений дружинника-воина, придворного, теолога и т.д.» [Лихачев, 1971, с. 107]. Это не нормативность устоявшейся риторической системы, ее готовых стилей и правил, как они представлены в «Поэтике» и «Риторике» Аристотеля и «Поэтическом искусстве» Буало, а, скорее, нормативность мгновенно узнаваемых эмблем и символов, устойчивых образов и фраз, играющих роль сигналов для читателя - участника церемониального литературного действа.

Коренной онтологизм российского сознания, единодушно признанный религиозными философами его основной родовой чертой, виден и здесь. Перед нами не каноны-понятия, а каноны-реалии, подобные геральдическим знакам и восходящие к культовой обрядовости. Эти нормы не придуманы - рождены. Поэтому они трудно согласуются с одним чистым выиыслом, предполагают неотделимость должного от сущего, то есть от реалистической конкретики. «В древнерусской литературе, - писал Д.С. Лихачев, - есть две тенденции: идеализирующая и конкретизирующая... в отдельных элементах условное изображение заменяется реальным» [Там же, с. 150]. А.И. Белецкий назвал подобную особенность «домыслом»: «Произведения, основанные на домысле, стремятся максимально приблизиться к жизненной правде, дать иллюзию воспроизведения подлинной действительности... пренебрежение к «выдумке» можно считать характерной чертой русской классической литературы... Оно ведет свое начало от литературы Древней Руси, которая развивалась под знаком историзма, решительно осуждая «басни и кощуны» (Цит. по: [Ромодановская, 1994, с. 29]).

По этим причинам переход русской литературы от «поэтики под знаком риторики» к новому уровню художественной правды, который обеспечивался новой мерой авторской свободы от канонов готового слова, был не «мятежным», а естественным. Его знаком стало появление произведений с артикулированным спонтанным сюжетом, таким как «Житие» Аввакума (среди произведений, готовивших его, указываются «Поучение» Мономаха, «Моление» Даниила Заточника, «Хождение Афанасия Никитина за три моря» и др. [Гусев, 1964, с. 44]), «Письма русского путешественника», «Монологи в прозе» Н.М. Карамзина, «Былое и думы», «Письма из Франции и Италии», «С того берега», «Концы и начала» А.И. Герцена, лирико-философские миниатюры и рассказы И.С. Тургенева, В.М. Гаршина, В.Г. Короленко, И.А. Бунина и др.

Обычно появление произведений, артикулирующих спонтанный сюжет, связано с усиливающейся динамикой социально-духовной жизни, со сменой или коррекцией мировоззренческих установок. Это периоды напряженной рефлексии и критики сложившихся представлений и норм, в том числе и канонов литературного творчества. Литература как бы начинает ощущать свою риторикотехнологическую избыточность, она размыкает границы, переступает через рампу, отделяющую ее от жизни и смыкается с полулитературной словесностью. Это вы- 
ражается, в частности, в активизации жанрового репертуара естественного дискурса. Герцен называл это «ближайшим писанием к разговору» - свободные воспоминания и размышления, беседа, дневник, исповедь, путевые заметки и т.п.

Произведения со спонтанным сюжетом нередко рефлектируют свою структуру на всех уровнях, включая род и жанр. Это книги с «прозрачными стенками», рождающиеся на глазах у читателя. Если мы вспомним одно из последних оживлений литературы такого рода, связанное с нашими перестроечными переменами, а их начало, как мне кажется, надо относить не ко второй половине восьмидесятых, а к 1960-м годам, то обнаружим целую волну произведений, несущих в себе вышеназванное свойство. Речь идет о так называемой лирической прозе - термин, вошедший в оборот с легкой руки А. Синявского и не совсем точно отражающий художественные особенности данной прозы. Точнее, на мой взгляд, определение «феноменологическая проза», потому что феноменологичен предмет ее изображения. Его непременная компонента - непосредственно выраженное авторское переживание изображаемого, в том числе и его рефлексии собственной поэтики, что не всегда укладывается в объем понятия «лирика».

«Я ищу чего-то, что не походило бы на роман, - пишет в «Траве забвения» В. Катаев. - Отсутствие интриги для меня недостаточно. Я хочу, чтобы сама структура была другой» [Катаев, 1969, с. 267]. В. Солоухин обсуждает эту тему с воображаемым собеседником в самом начале повести «Капля росы»: «Ну, а теперь расскажи мне, что ты сейчас пишешь. - Я пишу книгу. - Повесть? - Не совсем. Роман? - Вряд ли. - Так что же ты пишешь в конце концов? - Книгу» [Солоухин, 1974, с. 246]. Задумывался над подобным вопросом и К. Паустовский: «Как определить жанр тех вещей, о которых я упомянул («Третье свидание», «Наедине с осенью», «Ильинский омут» - Э.Б.). Не знаю. Это не рассказы в точном смысле слова, не очерки и не статьи. Это - не стихотворения в прозе. Это - записи размышлений, простой разговор с друзьями. Это - признание в любви нашей природе и всей России» [Паустовский, 1965, с. 4]. Д. Гранин ищет ответа в истории литературы: «Путевые картины Гейне мне кажутся идеалом прозы - в них свобода, о которой мечтаешь всегда - свобода от сюжета, от хронологии, от географии. Эта проза свободнее, чем стихи. О чем она? В том-то и секрет ее, что она ускользает от подобного вопроса» [Гранин, 1974, с. 7].

Спонтанный сюжет непредсказуем, и в этом заключается его важная функция, которая не отменяет, а дополняет роль других сюжетных принципов. Эту его дополнительность мы чувствуем в неожиданных для самого автора поворотах действия и поступках его героев. Она и в известном пушкинском признании о Татьяне, «выкинувшей штуку, выскочившей замуж», и в знаменитом словечке «вдруг» в романах Достоевского, и в неожиданных до невероятности сюжетных поворотах у А. Платонова, и в ахматовском «растут стихи, не ведая стыда» и во многом другом.

Проблема спонтанного сюжета - это вопрос не только о «границах личного творчества в предании» (А.Н. Веселовский), то есть о соотношении традиции и новации. Обсуждение этой давней темы привело к выводу о невозможности творчества вне устойчивых форм и смыслов, которые обеспечивают само понимание между людьми. Так автор не может не опираться на естественный язык и его трансформу - художественную речь во всем объеме выработанных ею средств, если он рассчитывает на внятность своего высказывания. Проблема спонтанности творчества и спонтанного сюжета в частности ставит вопрос Платона о модусе самой авторской новации, о соотношении в ней рассудительности и одержимости, сознания и наития.

Закончить тему хочется высказываниями двух великих художников слова М. Цветаевой: «Я давно перестала делить стихи на свои и чужие...Я не знаю авторства» [Цветаева, 1991, с. 41-42]; «Все мое писание - вслушивание. Точно вещь 
уже где-то точно и полностью написана. Работа поэта сводится к исполнению духовного (не своего) задания» [Письма Марины Цветаевой, 1969, с. 207]; и Гете: «Мы находимся на правильном пути, когда думая, мы не отдаем себе отчета, о чем мы думаем, тогда все происходит само собой, как подарок... Никакое размышление не помогает мысли; выдумки должны приходить к нам, как свободные божьи дети, и говорить: вот мы» [Гете, 1975, с. 28].

\section{Литература}

Аверинцев С.С. Древнегреческая поэтика и мировая литература // Поэтика древнегреческой литературы. М.,1981.

Аверинцев С.С. Мы призваны в общение // София - Логос. Киев, 2001.

Аристотель. Поэтика // Аристотель и античная литература. М., 1978.

Белый А. Настоящее и будущее русской литературы // Белый А. Символизм как миропонимание. М.,1994.

Гете И.В. Об искусстве. М., 1975.

Гусев В. Протопоп Аввакум Петров - выдающийся русский писатель XVII в. // Житие протопопа Аввакума. М., 1964.

Иванов В.И. Родное и вселенское. М.,1994.

Катаев В.П. Трава забвения. Святой колодец. М.,1969.

Лихачев Д.С. Поэтика древнерусской литературы. Л., 1971.

Лосев А.Ф. Философия. Мифология. Культура. М.,1991.

Монтень. Опыты. М., 1991.

Паустовский К.Г. Избранная проза. М., 1965.

Письма Марины Цветаевой // Новый мир. 1969. №4.

Платон. Собрание сочинений: в 4 т. М., 1990. Т.1; М., 1993. Т.2.

Ромодановская Е.К. Русская литература на пороге нового времени. Новосибирск, 1994.

Солоухин В.А. Избранные произведения в двух томах. Т. 2. М., 1974.

Франк С.Л. Русское мировоззрение. СПб., 1996.

Цветаева М. Об искусстве. М.,1991. 